\title{
A FRATERNIDADE COMO PRINCÍPIO ORIENTADOR NOS CASOS DE BULLYING
}

\section{THE FRATERNITY AS GUIDING PRINCIPLE IN THE CASES OF BULLYING}

\author{
Ricardo Bispo Razaboni Junior ${ }^{1}$ \\ Lafayette Pozzoli ${ }^{2}$
}

Data de Recebimento: $12 / 04 / 2018$

Data de Aprovação: 03/08/2018

\section{RESUMO}

O presente trabalho, de cunho dedutivo, objetiva analisar o princípio da fraternidade como possível pilar para o combate aos casos de bullying. Para isso, abordam-se, inicialmente, os principais aspectos acerca do fenômeno bullying, com a finalidade de introduzir o leitor ao assunto. Posteriormente, analisam-se os Direitos Humanos, lugar onde a fraternidade foi reconhecida como princípio norteador. Por fim, estuda-se o princípio da fraternidade e a

\footnotetext{
${ }^{1}$ Mestrando em Teoria do Direito e do Estado pelo Centro Universitário Eurípides Soares da Rocha de Marília/SP. Graduado em Direito pela Fundação Educacional do Município de Assis FEMA. Membro do Grupo de Pesquisa DiFuSo - Direitos Fundamentais Sociais, sob a liderança do Prof. Dr. Teófilo Marcelo de Arêa Leão Júnior, cadastrado no diretório acadêmico de pesquisa do CNPq. Realiza Estágio-Docência na graduação do curso de Direito do Centro Universitário Eurípides Soares da Rocha de Marília/SP. Professor da Nova concursos e Federal Concursos e pós-graduação em São Paulo. Professor da Autoridade Concursos em Assis-SP. Advogado. razabonij@gmail.com
}

\footnotetext{
${ }^{2}$ Advogado. Professor, Pró-Reitor de Pós-Graduação, Pesquisa e Extensão e Coordenador do Mestrado em Direito no UNIVEM. Professor e foi Chefe de Gabinete na PUC-SP. Possui graduação, Mestrado e Doutorado em Filosofia do Direito pela PUC-SP. Pós-Doutorado pela Universidade La Sapienza, Roma. Líder do Grupo de Pesquisa: GEP Grupo de Estudos e Pesquisas - Direito e Fraternidade - Univem. Membro do Conselho Editorial da Revista de Direito Brasileira - RDBras, do CONPEDI. Avaliador para cursos de direito INEP/MEC. Foi membro da Comissão de Ensino Jurídico, do Tribunal de Ética TED-1 e da Comissão da Pessoa com Deficiência da OAB/SP. Foi sócio efetivo do IASP - Instituto dos Advogados de São Paulo. Temas de pesquisa: dignidade da pessoa humana, ética, direito e fraternidade, direito como função promocional da pessoa humana. lafayette@lafayette.pro.br
} 
função promocional da pessoa humana, assuntos intrinsecamente ligados. Assim, concluí-se que o bullying pode ser combatido em sua origem, desde que utilizado de forma correta os ensinamentos do princípio da fraternidade.

\title{
PALAVRAS-CHAVE
}

Bullying. Cyberbullying. Intimidação Sistemática. Fraternidade. Função promocional da pessoa humana.

\begin{abstract}
The present work, of a deductive nature, aims to analyze the principle of fraternity as a possible pillar for the fight against bullying cases. For this, the main aspects about the bullying phenomenon are initially addressed, in order to introduce the reader to the subject. Subsequently, Human Rights are analyzed, where the fraternity was recognized as guiding principle. Finally, we study the principle of fraternity and the promotional function of the human person, subjects intrinsically linked. Thus, it was concluded that bullying can be tackled in its origin, provided that it correctly uses the teachings of the principle of fraternity.
\end{abstract}

\section{KEYWORD}

Bullying. Cyberbullying. Systematic Intimidation. Fraternity. Promotional function of the human person. 


\section{INTRODUÇÃO}

O presente artigo tem por objetivo analisar o princípio da Fraternidade como fundamento pilar para resolução do problema social hodierno cognominado bullying.

Deste modo, propõe-se uma sistemática dupla, separando o trabalho em duas partes, quais são: análise do fenômeno bullying e o princípio da Fraternidade. Tal divisão se justifica para facilitar a compreensão do leitor.

Assim, observar-se-á em primeiro plano o que é o bullying, as pessoas envolvidas nesse problema social, as formas de manifestação da violência gerada pela intimidação sistemática originada pelo bullying, bem como o cyberbullying, modalidade atualmente em evidência, visto o crescimento do mundo virtual.

Em plano contínuo, analisar-se-á a teoria dos direitos humanos, com a conseguinte verificação do princípio da Fraternidade, que compõe núcleo essencial da terceira dimensão dos direitos fundamentais, bem como a função promocional da pessoa humana, assunto intrinsecamente ligado ao sentimento fraterno.

Por fim, justifica-se que não há o intuito de esgotar o tema, mas sim propor a evolução de um princípio que pode auxiliar no combate da violência, como in verbis, o bullying.

\section{O QUE É O BULLYING?}

Há um tempo não muito distante, o bullying, problema social que se observa hoje no sistema educacional mundial, era visto pelos adultos, como pais, responsáveis, professores e diretores de estabelecimentos de ensino, como brincadeiras pueris, que pertenciam e eram naturais à idade infantil ou adolescente. Não obstante a construção desse pensamento havia quem defendia tal comportamento como sendo uma iniciação à vida adulta, comparável até mesmo a um rito de passagem. (ALBINO; TERÊNCIO, 2009, p. 173)

Passado o tempo, há ainda pessoas que enxergam o bullying como sendo algo normal da infância e juventude, justificando-se com perguntas como: 
Quem nunca sofreu ou praticou gozações na escola? Quem nunca apelidou ou recebeu apelidos? Porém, ao contrário do exposto, tem-se que esse é um grave problema social, como se verifica em diversas pesquisas sobre a temática originadas após a década de 1970, cujo precursor fora o Professor Dan Olweus, da Universidade de Bergen, na Noruega. (ALBINO; TERÊNCIO, 2009, p. 173)

Partindo da premissa etimológica, a fim de construir uma identificação completa sobre o seu conceito, tem-se que a palavra bullying encontra origem na língua inglesa, sendo um termo derivado da palavra bully, o qual, por sua vez, não obtém significado exato. É possível aferir dois principais significados para o termo bully, quais são: a) quanto substantivo: alguém que usa sua força ou poder para amedrontar ou machucar quem é mais fraco e b) enquanto verbo: pressionar alguém para obter o que se quer. (ORSINI; SILVA, 2015, p. 287)

Na língua portuguesa, a palavra bully pode ser representada pelos substantivos "valentão", "tirano", "brigão", "fanfarrão" e "mandão", não obstante, pode ser representada também por meio dos verbos "ameaçar", " provocar", "oprimir", "intimidar", "maltratar" e "assustar". Assim, concluí-se que a palavra bullying reflete o significado de "ameaça", "intimidação", "assédio", "provocação", dentre outros.

Pois bem, em plano conceitual, verifica-se que o bullying pode ser considerado como uma oposição, negação a amizade, cuidado e respeito. Neste sentido, o agressor, sujeito ativo desse fenômeno, de modo impiedoso, expõe o agredido, sujeito passivo, às piores humilhações, desde apelidos perversos, até coações morais e físicas. Diante da sistemática agressão, o agredido se torna um mero objeto, o qual dificilmente encontrará coragem para se defender, permitindo a continua agressão sem qualquer providência. (CHALITA, 2008, p. 14)

De modo não diferente, tem-se ainda a ideia de que o Bullying, em âmbito escolar, significa a ação dos estudantes que se colocam em posição aparentemente superior aos demais estudantes, fato que corrobora na possibilidade de agressão, de forma reiterada, por vias físicas, verbais e psicológicas.

Deve-se, neste ponto, ressaltar que o bullying é uma violência, porém nem toda violência no ambiente escolar se caracteriza como bullying. Para a incidência do bullying (no ambiente escolar) deve haver comportamentos agres- 
sivos repetitivos com crianças ou adolescentes em situação de desigual poder, onde as vítimas encontram dificuldades para defesa.

Há três vetores para melhor identificação do bullying, quais são: a) frequência: a agressão ou violência deve ocorrer de forma sistemática, ou seja, repetitiva; b) intensidade: a violência deve originar sofrimento físico, psíquico ou moral; c) intencionalidade: a agressão deve ser intencional. (OLIVEIRA; CAMBI, 2015, p. 120)

Diversos são os fatos que podem levar alguém a praticar esse fenômeno, como: i) falta de limites nos processos educacionais no contexto familiar; ii) carência de um modelo de educação capaz de associar a autorrealização com atitudes socialmente produtivas e solidárias, o que leva os agressores a procurar se afirmar por meio de ações egoístas e maldosas; iii) vivência de situações momentâneas como separação traumática dos pais, ausência de recursos financeiros, doenças na família etc.; iv) falta de empatia (sentimento essencial para o exercício do altruísmo), o que faz com que essas crianças e adolescentes apresentem a transgressão como base estrutural de suas personalidades. (OLIVEIRA; CAMBI, 2015, p. 121)

Assim, tem-se que o bullying pode ser considerado como um conjunto de comportamentos antissociais, com crueldade e repleto de agressividade, tanto por meio psíquicos, quanto por meio físicos, realizados de forma intencional, insistentes e repetitivos, sem motivação evidente, por um bully (agressor que pode ser estudante ou professor), dentro de um ambiente escolar, contra alguém que se encontra em uma posição inferior (vítimas ou agredidos), as quais se sentem expostas a situações constrangedoras, humilhadas, ameaçadas, ridicularizadas e intimidadas. (DINIZ, 2016, p. 18-19)

Ressalta-se que se deve haver, para a existência do bullying, a intentio ordenada de molestar alguém ou de colocá-lo em estado de tensão. (DINIZ, 2016, p. 19)

Lembra-se que em 2015, em âmbito nacional, fora promulgada a Lei de Combate à Intimidação Sistemática (Lei n. 13.182/2015), a qual passou a considerar como intimidação sistemática - tradução ofertada pelo legislador à palavra inglesa - todo ato de violência física ou psicológica, intencional e repetitivo que ocorre sem motivação evidente, praticado por indivíduo ou grupo, 
contra uma ou mais pessoas, com o objetivo de intimidar ou agredir a vítima, causando dor e angústia, em uma relação de desequilíbrio de poder entre as partes.

Concluí-se, portanto, que esse fenômeno é uma das mais cruéis manifestações exteriorizadas no ambiente escolar, a qual o agressor vai gradativamente dizimando a auto-estima do agredido, com diversas ofensas e humilhações públicas, ridicularizando-o perante a escola e demais estudantes.

\subsection{Quais são os sujeitos envolvidos no bullying?}

Conforme se observa em estudos contemporâneos acerca da temática bullying, existem três formas de participação nesse fenômeno, sendo por meio do sujeito ativo ou agressor, sujeito passivo ou vítima e espectadores, que podem ser sujeitos ativos, passivos ou neutros na cena factual.

Importante salientar antes do estudo dos atores do bullying que é importante observar tal classificação de forma crítica, tendo em vista que há uma tendência a apresentar perfis pessoais de forma estanque e estereotipados. Ressalta-se que a classificação não observa de forma exata e precisa todos os sujeitos de um caso de bullying, mas tão somente informa aspectos observados na maioria dos casos estudados, de forma global, não baseada apenas na realidade brasileira.

Pois bem. O agressor, sujeito ativo ou bullies, é aquele que ataca as vitimas. Em regra, como observado pela Professora Maria Helena Diniz, o agressor tem algum transtorno mental ou problema psicológico, como ausência de afeto, carinho, atenção, compactuado com educação violenta ou permissiva, que o leva a usar da força física, e escolher sua vítima sem ter sido por ela provocado. (DINIZ, 2016, p. 19)

Observa-se, nesse ponto, a existência de duas formas, predominantes, porém não absolutas, de violência originada por agressores do sexo masculino e feminino.

$\mathrm{O}$ agressor do sexo masculino costuma praticar o bullying direto, $\mathrm{o}$ qual é aquele realizado por meio de agressões físicas e humilhações, como socos, empurrões, chutes, apelidos, insultos e outras atitudes discriminatórias, 
na qual se atinge de maneira imediata, física ou verbal, a vítima. (RAZABONI JUNIOR; MARGRAF; LEÃO JÚNIOR, 2018, p. 75).

Neste sentido, os agressores masculinos costumam atacar suas vítimas por meio de: a) agressões verbais, mediante: amplificação de "defeitos" estéticos, insultos, piadas, apelidos pejorativos e demais pilhérias; b) agressões físicas e violência: espancamento, chutes, socos, roubo ou extorsão de bens pessoais; c) agressões psíquicas: com uso de ameaça, chantagens, recados desaforados, humilhações, perseguições, amedrontamentos etc... d) virtualmente: meio pelo qual os agressões deixam de usar agressão verbal visual e escrita, passando a utilizar sites de relacionamento e meios para tornar eficaz o cyberbullying, principalmente pelo cyberstalking, o qual é uma perseguição virtual, ocorrida por redes sociais como Facebook. (DINIZ, 2016, p. 19)

A título de especulação, tem-se que o cyberstalking ocorre principalmente com a divulgação de fotos com imagens obscenas e vídeos íntimos sem consenso do parceiro (vítima), caso em que, geralmente, o cyberbullying é protegido pelo anonimato, pois age na sombra que a internet possibilita, por meio de perfil falso ou com senhas "roubadas", possibilitando a exposição da vítima de modo danoso a sua imagem na rede mundial de computadores. ${ }^{3}$

De modo diverso age a agressora do sexo feminino, onde o bullying, por costume, far-se-á por via indireta (ou omissão) ${ }^{4}$, ou seja, levando a vítima ao isolamento social, mediante a utilização de boatos, intrigas, difamação, desprezo, fofoca, etc... (DINIZ, 2016, p. 20)

Quanto às vítimas, tem-se que essa é aquela pessoa, aparentemente, passiva, introvertida ou tímida, podendo ser muito alta, muito baixa, insegu-

\footnotetext{
3 "Mas, quando a vítima de cyberbullying efetua denúncia e ingressa em juízo para obter reparação do dano, é possível que o advogado obtenha a quebra do número Internet Protocol (IP) do computador de onde saíram as mensagens lesivas, e identifique 0 agressor. $O$ autor do cyberbullying, em regra, para dificultar sua localização, faz uso de computadores de lan house. Convém lembrar que a Lei estadual paulista n. 12.228/2006 obriga as lan houses e cybercafés do Estado de São Paulo, sob pena de multa ou fechamento, em caso de reincidência, a: cadastrarem seus usuários, indicando endereço, horário e computador utilizado; proibirem entrada de menores de 18 anos após a meia-noite e exigirem autorização escrita dos pais para adolescentes entre 12 e 16 anos e acompanhamento de crianças de até 12 anos pelos pais ou responsáveis; e, ainda e) sexualmente, praticando assédios, estupros etc." (DINIZ, 2016, p. 19)

${ }^{4}($...) "b) bullying indireto: o qual ser perfaz por meio de intimidações psicológicas, que suscitam o isolamento da vítima, por meio de calúnias, injúrias, difamações, pilhérias e outros meios atemorizantes, ou seja, a propalação de histórias danosas a imagem das vítimas". (RAZABONI JUNIOR; MARGRAF; LEÃO JÚNIOR, 2018, p. 77)
} 
ra, pouco sociável, frágil fisicamente, gorda, deficiente física ou de gagueira, excessivamente inteligente, feita, bonita, novata na escola, inábil desportivamente etc.

Dentro dessa perspectiva, pode-se dizer que há três subespécies de vítima, ou seja, três "tipos" de vítimas, quais são: a) a vítima típica, que é aquela comum, que sofre ou angustia pela agressão física ou verbal por estar, aparentemente, fora dos "padrões"; b) a vítima provocadora, a qual provoca a agressão que, em um momento posterior, irá lhe afligir. Em outras palavras, tal vítima provoca uma ação negativa do agressor, que posteriormente não poderá suportar; c) vítima agressora, que é aquela que sofreu uma agressão por meio do bullying e que, num movimento de cascata, passa a agredir os outros que se encontram em um estado de aparente inferioridade. Assim, concluí-se que a vítima agressora reproduz os ataques sofridos anteriormente em suas vítimas. (RAZABONI JUNIOR; MARGRAF; LEÃO JÚNIOR, 2018, p. 76)

Não obstante às figuras ativas (agressor) e passivas (vítima) do bullying, tem-se que para existir um ânimo por parte do agressor, devem-se haver aplausos de uma platéia, pois se isso não existir, não haverá razões para a agressão. Assim, tem-se que as figuras dos espectadores são de grande importância em uma ocorrência de bullying.

Tal como a figura da vítima, os espectadores também podem ser subdivididos em três espécies, quais são: a) os espectadores ativos, os quais aplaudem, apóiam a violência ocorrida, porém sem participar da agressão; b) os espectadores passivos, os quais não interferem na agressão pelo medo de se tornar uma vítima; c) os espectadores neutros, que nem apóiam, nem ficam angustiados pela dor da vítima. (RAZABONI JUNIOR; MARGRAF; LEÃO JÚNIOR, 2018, p. 77)

\subsection{Quais são as formas de manifestação do bullying?}

Conforme ensinado pelo legislador contemporâneo, na égide do Programa de Combate à Intimidação Sistemática - cognominação ofertada como tradução da palavra inglesa bullying - tal fato, agressão, pode ocorrer de diversas formas. 
Vê-se, conforme doutrina, que o bullying pode ser dividido em duas modalidades, sendo: a) bullying direto: o qual ocorre com agressões físicas e humilhações, como socos, empurrões, chutes, apelidos, insultos e outras atitudes discriminatórias, atingindo de maneira imediata, física ou verbal, a vítima; b) bullying indireto: o qual ocorre mediante intimidações psicológicas, que suscitam o isolamento da vítima, por meio de calúnias, injúrias, difamações, pilhérias e outros meios atemorizantes, ou seja, a propalação de histórias danosas a imagem das vítimas. (RAZABONI JUNIOR; MARGRAF; LEÃO JÚNIOR, 2018, p. 3- 4)

No que tange as formas de agressão, a primeira se faz por meio da agressão verbal, a qual pode ser realizada por meio de insultos, xingamentos e apelidos pejorativos, constituindo uma agressão direta à vítima, ou seja, por meio do bullying direto.

Em segundo plano sugere-se a existência do bullying moral, o qual é originado por meio de difamações, calunias, disseminação de rumores, dentre outras práticas que suscitam a propagação de histórias imorais contra a vítima, sendo tal fato constituído por meio do bullying indireto, já que não há agressão de forma direta, imediata à vítima.

Não obstante, verifica-se o bullying sexual, que é originado por meio do assédio sexual contra à vítima, a indução ou o abuso concreto contra a mesma, perfazendo-se por meio direto.

Em outro plano, diferente do bullying moral, porém com certa semelhança, há o bullying social, que consiste em atos que causam o isolamento e a exclusão da vítima, podendo ser considerado um bullying indireto.

Há também o bullying psicológico, que é realizado por atitudes de perseguição, amedrontamento, intimação, dominação, manipulação, chantagens e infernizações (DINIZ, 2016, p. 21). Tal fato pode se originar tanto pelo meio indireto, quanto direto.

Por sua vez, o mais clássico meio de origem do bullying direto é o físico, que nasce a partir de agressões físicas concretas contra a vítima, com chutes, socos, empurrões, entre outras agressões.

Como penúltima forma de se concretizar a intimidação sistemática, pode-se citar o bullying material, que consiste em um meio direto ou indireto de 
realização da referida agressão, o qual se perfaz por meio de furtos, roubos, destruições de pertences da vítima e outras formas que agridam materialmente o sujeito passivo.

Por fim, e de grande importância, tem-se o bullying virtual ou cyberbullying, que pode também ocorrer tanto pela forma direta, quanto pela indireta, consistente em atitudes realizadas por meio da rede mundial de computadores, geralmente por aplicativos como Facebook, Twitter e Instagram. Pelo meio virtual o agressor por depreciar, enviar mensagens intrusivas da intimidade da vítima, enviar ou adulterar fotos e dados pessoais que originem sofrimento, angustia e dor ou com intuito de criar constrangimento social e psicológico. (DINIZ, 2016, p. 21)

Dada a importância à temática, analisar-se-á a seguir a figura específica do cyberbullying ou bullying virtual.

\subsection{Cyberbullying}

Como já alusivo acima, o cyberbullying constitui uma das formas em que o bullying pode ser praticado, sendo esse pelo meio virtual, com uso de aplicativos e programas os quais proporcionam e atiçam a imaginação do agressor para praticar atos de crueldade e constrangimento contra a vítima.

Tal meio de agressão é realizado por meio das tecnologias de informação e comunicação (TIC), sempre com objetivo de excluir socialmente, ameaçar, envergonhar ou insultar alguém. (MANDIRA, 2017, p. 22)

Em sentido similar, há a conceituação de Telma Brito Rocha (2012, p. 14) que define o cyberbullying como "uma prática de violência, realizada por um indivíduo que humilha, intimida ou assedia outro indivíduo, ou grupos de indivíduos, por meio das tecnologias digitais"

Não obstante, como forma de complemento, utiliza-se a dogmática de D. Muir (2005, p. 60), que explica: “Bullying and harassment by virtual means fast became a widespread phenomenon among diverse groups of children and young people. Cyber bullying may be conducted by sending phone text messages, images and e-mails, as well as through online discussion groups and personal web pages. Initial observations conclude that bullying by virtual means 
intensifies the experience of harm to a targeted child" 5

Alguns autores entendem o cyberbullying como sendo um fenômeno totalmente diferente do bullying, alegando que a utilização de aparelhos eletrônicos geraram um novo meio de interação, fortalecendo a comunicação e o relacionamento entre pessoas. Assim, expõe essa corrente que a agressão em ambiente diverso ao que o bullying geralmente acontece torna o cyberbullying algo único e com grande diferenciação, não sendo assim uma espécie de bullying, mas sim um fenômeno novo, com outro tipo de violência, que tem crescimento e aperfeiçoamento que acompanham a tecnologia comunicativa. (LAW ET AL; WALKER ET AL, 2011; ROCHA, 2012 apud GARCEZ, 2014, p. 24)

De modo oposto, vêem-se os defensores da ideia de que o cyberbullying constitui uma forma de bullying social, o qual somente utiliza ferramentas tecnológicas para a mesma finalidade que se atingiria pessoalmente. (SCNHEIDER ET AL, 2012; OLWEUS, 2012; ANG E GOH, 2010; PATCHIN E HINDUJA, 2006; MENESINI, 2012 apud GARCEZ, 2014, p. 24)

Dan Olweus, considerado o pioneiro em estudos sobre a temática, com seu primeiro trabalho publicado em 1970 (RAZABONI JUNIOR; LEÃO JÚNIOR; MARGRAF, 2018, p. 74) se mostra adepto a segunda corrente. Conforme expõe em sua pesquisa, o cyberbullying não é um fenômeno tão praticado, pois, diante de estudos feitos na Noruega e nos Estados Unidos, verifica-se uma baixa prevalência desse novo fenômeno, que não trouxe grande aumento e nem fez novas vítimas e agressões, tendo em vista que são praticamente as mesmas pessoas que estão envolvidas de alguma forma com o bullying tradicional (OLWEUS, 2012). Assim, observa-se que o cyberbullying nada mais é do que uma extensão da prática do bullying tradicional, na maioria dos casos.

Como forma de resolução da problemática, Dan Olweus recomenda a utilização de pesquisas a fim de relacionar as duas modalidades de bullying, ao invés de estudar o cyberbullying de forma isolada. Deste modo, tem-se que as

\footnotetext{
${ }^{5}$ Bullying e assédio por meios virtuais rapidamente se tornaram um fenômeno generalizado entre diversos grupos de crianças e jovens. $O$ cyberbullying pode ser conduzido pelo envio de mensagens de texto por telefone, imagens e e-mails, bem como por meio de grupos de discussão online e páginas pessoais. Observações iniciais concluem que o bullying por meios virtuais intensifica a experiência para de agressão à vítima. Muir, Déborah. Violence against children in cyberspace. Bangkok: ECPAT International, 2005, p. 60. Tradução ofertada por: SANTOS, Erick. O fenômeno bullying e os direitos humanos. Revista de Direito Educacional, vol. 3, jan-jun, 2011, p. 51-107. d
} 
escolas poderão direcionar seus esforços para campanhas anti-bullying, reduzindo por conseguência a já baixa incidência do cyberbullying. (OLWES, 2012)

Andrea Müller Garcez (2014, p. 25) observa a distinção entre o bullying e o cyberbullying de acordo com diversos pesquisadores. Assim, verifica-se o seguinte:

a) A desterritorialização das agressões - por não acontecer em um ambiente físico e restrito, as agressões perseguem os alvos em diferentes espaços, mesmo naqueles onde elas estariam "a salvo" do bullying (como em casa, ou fora da escola), tornando as agressões mais duradouras e muitas vezes sem a possibilidade de um refúgio (Rocha, 2012; Tokunaga, 2010; Shariff, 2011);

b) potencial multiplicativo - as mensagens publicadas podem ser compartilhadas, baixadas e republicadas, viralizadas (Rocha, 2012; Shariff, 2011; Zuin, 2012) o que pode lhes conferir perenidade;

c) A possibilidade do anonimato pode encorajar as agressões (Tokunaga, 2010; Shariff, 2011; Berguer et al, 2011);

d) Uma mudança nas relações de poder - estas persistem, mas sua natureza é diferente no cyberbullying. O conhecimento tecnológico pode ser uma maior fonte de poder do que a força física, que é considerada um fator importante no caso do bullying (Law et al 2011; Berguer et al, 2011; Patchin e Hinduja, 2006);

e) A amplitude da audiência - o número de "testemunhas" pode alcançar a casa dos milhares. A audiência não fica restrita a um ambiente (amigos da escola), a agressão pode ser vista por familiares e amigos de outros lugares frequentados pelo alvo - clube, cursos, vizinhos (Law et al, 2011; Rocha, 2012; Zuin, 2012);

f) Em ambientes online os papéis são menos distinguíveis - as vítimas podem se sentir mais seguras para retaliar, aumentando a probabilidade de se tornarem também agressores. Uma agressão inicial pode iniciar um encadeamento de agressões posteriores entre dois indivíduos, tornando-se difícil distinguir quem é a vítima e quem é o agressor (Law, et. al., 2011);

g) O critério da intenção de ferir não é válido quando se trata de relações pela internet - se já é difícil identificar a intenção no 
bullying social que acontece face-a-face, mais difícil ainda quando se leva em conta a natureza específica de mensagens eletrônicas, em que o contato visual e a entonação são inexistentes, o que pode levar a erros de interpretação (Law et at, 2011; Berguer et al, 2011);

h) O critério da repetição do gesto agressor não é válido basta que a mensagem tenha sido postada uma única vez para que ela seja vista e compartilhada muitas e muitas vezes, por um número quase ilimitado de pessoas (Law et at, 2011; Berguer et al, 2011);

i) A permanência das imagens: algumas imagens se fixam de forma tal que se torna muito difícil para o sujeito que sofreu a agressão desfazer-se daquela identidade (Zuin, 2012).

Em outro plano, pontua-se que além da discussão acerca do cyberbullying ser ou não ser uma modalidade de bullying, tem-se a divergência de nomenclaturas e semânticas no que se refere às violências em âmbito virtual.

Diversos são os termos utilizados para violências virtuais, como cyberharassment, online aggression, internet harassment, eletronic aggression, eletronic bullying, cyberteasing, cyberarguing, ou ainda cyberattacking. O que ocorre é que em diversas vezes tais termos são utilizados como sinônimos ou traduções de cyberbullying, porém, em outras há a indicação de diferenças e particularidades. (GARCEZ, 2014, p. 27)

Nesse sentido, observa-se a corrente que defende o cyberbullying como agressão realizada somente via aparelho celular, enquanto o cognominado bullying online seria a nomenclatura destinada às agressões gerais via internet.(LAMPERT e DANOSO, 2012; SLONJE e SMITH, 2008; apud GARCEZ, 2014, p. 27)

Em outro sentido, verifica-se um conceito mais amplo de cyberbullying. Para a segunda corrente, somente a vítima pode avaliar a extensão da agressão e consequentemente do dano sofrido, independente de verificação da intenção do agressor. "Assim, consideraram em sua pesquisa com graduandos que receberem mensagens indesejáveis (com símbolos de afeto, como poesia ou música, com cobranças de mensagens ou com necessidades excessivas), pode ser caracterizado como cyberbullying". (GARCEZ, 2014, p. 27) 
Por fim, têm-se os defensores do termo cyberviolência, que seria uma forma ampla de alcançar toda e qualquer violência no âmbito virtual, encontrando-se o cyberbullying dentro dessa cognominação. (BERGUER, 2011)

Apesar das discussões sugeridas, acredita-se ainda que a grande problemática acerca do presente assunto é a dificuldade de se controlar as agressões oriundas da internet, tendo em vista que há grandes possibilidades do anonimato do agressor não ser desvendado (WALKER; SOCKMAN e KOEHN, 2011).

\section{DIREITOS HUMANOS: O PRINCIPAL PASSO PARA A FRATERNIDADE}

Acredita-se que não há grande diferença entre direitos humanos e fundamentais, sendo que caso aceite que haja esta diferenciação, não ultrapassaria o plano conceitual. Nesse sentido, tem-se, materialmente falando, que ambos os direitos supracitados apresentam uma visão à proteção e à promoção da dignidade da pessoa humana. Entretanto, no que se refere ao conteúdo, pouca ou nenhuma diferença há entre eles

A histórica ampliação e transformação dos direitos do homem torna difícil uma definição exata em um conceito sintético e preciso. Tal ampliação e transformação conceitual pode ser explicada de forma simples, já que "o que parece fundamental numa época histórica e numa determinada civilização não é fundamental em outras épocas e em outras culturas" (BOBBIO, 2004, p. 13). Aumenta-se ainda mais tal dificuldade quando vários cognomes são ofertados para esses direitos, como: direitos naturais, direitos humanos, direitos do homem, direitos individuais, direitos públicos subjetivos, liberdades fundamentais, liberdades públicas e direitos fundamentais do homem (SILVA, 2014, p. 177).

Assim, a diferenciação encontrada entre tais diplomas legais é o local que foram consagrados, sendo os direitos humanos (Declaração Universal de Direitos do Homem de 1948) em plano internacional, enquanto os direitos fundamentais em plano nacional (Constituições).

Nesse sentido, tem-se que os Direitos Humanos/Fundamentais repre- 
sentam um conjunto institucionalizado de normas - lê-se direitos e garantias - do ser humano, que tem como objetivo substancial a observação à dignidade, por intermédio da proteção ao arbítrio estatal com a conseguinte implantação de ideais de condições mínimas de vida e desenvolvimento da personalidade humana (MORAES apud PANCOTTI, 2009, p. 85).

Não obstante, entendem-se esses direitos como prerrogativas e instituições consagradas pelo direito positivo, a fim de garantir uma convivência digna, livre e igual a todos os conviventes, tratando-se de situações jurídicas sem as quais não há convivência ou sobrevivência, direitos que necessitam de reconhecimento e efetivação em relação a todos (SILVA, 2000, p. 495-496).

Em plano continuo, depreende-se a ideia de que direitos fundamentais são universais, inalienáveis, imprescritíveis, irrenunciáveis, invioláveis, indivisíveis, interdependentes e inexauríveis. Entretanto, no plano da irrenunciabilidade e inegociabilidade, há que sustente que sendo os direitos fundamentais essencialmente direitos de liberdade do cidadão, "nada mais coerente do que aceitar a liberdade de não exercitá-los, de deles dispor ou de a eles renunciar". Neste sentido, renunciar direitos fundamentais seria um básico exercício libertário, imanente à essência dos direitos fundamentais (STERN e BLECKMANN apud SILVA, 2005, p. 129). Este pensamento revela a teoria liberal acerca dos direitos fundamentais.

Em plano contraposto, Virgílio Afonso da Silva (2008, p. 129) apresenta a ideia de que é possível perceber uma tendência teórica democrática-funcional no Brasil, sendo coerente sustentar a irrenunciabilidade e inalienabilidade dos direitos fundamentais. Nesse sentido, Böckenförde expõe que o "ponto de partido da teoria democrático-funcional dos direitos fundamentais é sua compreensão a partir da sua função pública e política" sendo " A garantia de direitos fundamentais como esferas de liberdade tem lugar primeiramente para possibilitar e proteger esse processo" (BÖCKENFÖRDE, 1991, p. 133).

Nesse sentido, concluí-se que os direitos fundamentais não são precipuamente direitos individuais contra abusos estatais, como apresentado por muitos doutrinadores, mas elementos essenciais, ou melhor, fundamentais da ordem democrática, sendo compreensível que não estejam, se se partir desse paradigma, à disposição de seus titulares. (SILVA, 2005, p. 130). 
Entretanto, ressalta-se que não são essas teorias (liberal e democráticofuncional) que explicam a função dos direitos fundamentais na ordem jurídica e social. A Constituição brasileira esta fundada em uma concepção social-estatal dos direitos fundamentais, sendo o Estado garantidor de condições sociais necessárias para a realização das liberdades fundamentais a partir dos direitos fundamentais. (SILVA, 2005, p. 130).

Faz-se necessário, nesse ponto, a observação das dimensões, estudo que dará ensejo ao início do estudo em epígrafe, ou seja, a fraternidade.

Os direitos de primeira geração ou de liberdade, são aqueles que tem por titular um indivíduo, sendo oponíveis ao Estado. Traduzem como faculdades ou atributos da pessoa e ostentam uma subjetividade que, na visão de Bonavides, é o traço mais característico. Não obstante, mostram-se ainda como direitos de resistência ou oposição perante o Estado, sendo de característica status negatious de Jellinek. (BONAVIDES, 2011, p. 563-564).

No plano dos direitos de segunda geração, observa-se como pilar principal a igualdade, traduzindo-se por direitos sociais, entendidos como direitos de grupos sociais menos favorecidos, e que impõem ao Estado uma obrigação de fazer, de prestar direitos positivos, como in verbis a saúde, educação e moradia. Baseiam-se na igualdade material, ou seja, na redução de desigualdades, no pressuposto de que não é suficiente possuir liberdade sem a existência de condições mínimas para exercê-la. (RAZABONI JUNIOR, LEÃO JUNIR, 2018, p. 48)

Em terceiro plano, porém não último, já que há teorias que propõe outras dimensões dos direitos fundamentais, há a fraternidade, com foco na coletividade, diferentemente das dimensões anteriores. (PANCOTTI, RAZABONI JUNIOR, LEÃO JÚNIOR, 2018, p. 128)

Deste modo, estudar-se-á a seguir a fraternidade, como ensejo para demonstrar sua necessidade para o combate ao bullying.

\subsection{Fraternidade e função promocional da pessoa humana}

Tem-se que a Fraternidade é um valor chave para inspirar e moldar relações jurídicas. Além disso, constituiu, juntamente com os valores de igualdade e a liberdade, o tripé da Revolução Francesa. (TORRES; MUNIZ, 2015, p. 164) 
O significado semântico da Fraternidade consiste na "união ou convivência como irmãos; harmonia entre os homens".

Conforme afirma Marco Aquini (2008, p. 137):

A fraternidade é considerada um princípio que está na origem de um comportamento, de uma relação que deve ser instaurada com os outros seres humanos, agindo uns em relação aos outros, o que implica também a dimensão da reciprocidade. Nesse sentido, a fraternidade, mais do que como um princípio ao lado da liberdade e da igualdade, aparece como aquele que é capaz de tornar esses princípios efetivos.

Assim, tal princípio representa a reciprocidade de ações entre indivíduos, sendo a partir dela possível concretizar os ideiais ensinados pelos princípios da liberdade e igualdade, representantes magnos da primeira e segunda dimensão dos direitos fundamentais. Conforme exposto por Guilherme de Luca e Lafayette Pozzoli, a Fraternidade deve ser recuperada e colocada em efetividade com emergência, tendo em vista o momento filosófico social que a humanidade se apresenta, repleta de sentimentos individualistas. (LUCA; POZZOLI, 2015, p. 233)

Destaca-se que a Fraternidade é um princípio com capacidade pilar de nortear todo o ordenamento jurídico, interno e externo, além de todas as relações humanas, nas mais diversas sociedades, a qual provê forças para a dignidade da pessoa humana, que deve ser compreendida como um valor supremo que atrai todo o conteúdo dos direitos fundamentais do homem, desde o direito à vida, até porque não é possível imaginar o direito à vida sem dignidade, fato que concluí a ideia que o direito à vida deve ser compreendido pelo direito à vida digna, ou seja, de forma extensiva em seu valor.

Nesta seara, a Fraternidade tem importante papel no mundo globalizado hodierno, visto que precisa ser reconhecido como princípio universal de caráter político. (BAGGIO, 2009, p. 15 apud LUCA; POZZOLI, 2015, p. 233) ${ }^{6}$

\footnotetext{
${ }^{6} \mathrm{Na}$ medida em que vivemos em um mundo globalizado, não só econômica, mas culturalmente, o valor da tolerância e do respeito à alteridade se faz cada vez mais necessário, devendo o Estado, na qualidade de árbitro dos valores sociais, desfazerse de qualquer liame religioso que impeça o correto exercício de sua função em prol do verdadeiro interesse público (TODELO, 2004, p. 240).
} 
Sem dúvidas, a Declaração Universal dos Direitos Humanos, da ONU, representou um marco histórico para a defesa e concretude de direitos do homem. Observa-se que a Fraternidade, não por acaso, foi disposta no referido diploma em seu primeiro artigo: "todos os homens nascem livres e iguais em dignidade e direitos. São dotados de razão e consciência e devem agir uns aos outros com espírito de fraternidade".

De forma semelhante, em plano interno, a Constituição Federal de 1988 trouxe a fraternidade logo em seu preâmbulo, fazendo referência a necessidade de uma "sociedade fraterna, pluralista e sem preconceitos".

Além de sua importância como princípio jurídico, a Fraternidade se mostra como princípio social, pois prevê a possibilidade de integração entre povos e nações, com fundamentação cosmopolita, onde as necessidades essenciais podem ser suprimidas pela amizade ou por acordos assinados. (POZZOLI; CRUZ, 2010, p. 38)

Como se não bastasse, tanto os princípios da dignidade humana, liberdade, igualdade - todos com referência nesse trabalho-, quanto o princípio da fraternidade, tem íntima ligação com a função promocional da pessoa humana.

A função promocional da pessoa humana muitas vezes é associada ao direito punitivo do Estado (POZZOLI, TOLEDO, 2017, p. 187), que visa obter comportamentos desejáveis, "razão pela qual não importa em proibir, obrigar ou até mesmo permitir, mas sim em estimular comportamentos, por meio de medidas diretas e/ou indiretas, de elevação, respeito e cumprimento de todos os preceitos que assegurem a dignidade humana (LUCA; POZZOLI, 2015, p. 241). Nesse sentido, tem-se a lição de Franco Montoro, que ensina:

O fim do Direito é ordenar a vida da sociedade, orientando a conduta de seus membros e a atividade de suas instituições. Para esse objetivo, ele estabelece normas e procura garantir a eficácia das mesmas, atribuindo conseqüências positivas a seu cumprimento e negativas ou punitivas à sua violação. Ver no Direito apenas o aplicador de sanções punitivas é diminuí-lo. (1999, p. 252).

A Fraternidade tem papel essencial na efetiva mudança social, pois: 
Um ordenamento promocional, característico de um Estado Social intervencionista, a técnica típica das medidas indiretas é o encorajamento, pelo qual se busca tornar o comportamento desejado mais fácil ou, uma vez realizado, produtor de consequências agradáveis, mediante a utilização de duas operações: a sanção positiva propriamente dita, sob a forma de recompensa (prêmio) de um comportamento já realizado; e o incentivo ou facilitação, que precede ou acompanha o comportamento que se pretende encorajar (BOBBIO, 2007, p. 16-17).

Porém, observa-se a ideia de que o Direito deve ser visto como um instrumento promocional da pessoa humana, sendo que a fraternidade constitui um direito. Em outras palavras, não se pode entender a função promocional com um meio somente de punição, mas também de promoção e valorização da pessoa, visto e devidamente ligado ao princípio da fraternidade, o qual tem por objetivo organizar a vida da sociedade. (LUCA; POZZOLI, 2015, p. 241).

\section{CONSIDERAÇÕES FINAIS}

Conclui-se que o bullying obstrui a construção de uma vida plena e digna, bem como o crescimento sociocultural de seus envolvidos. Afeta o direito a uma vida saudável, qual leva à construção de uma qualidade de vida, que deve objetivar a democracia, igualdade, procurando livrar o homem de seus males e proporcionando-lhes benefícios.

Como forma de combate a esse problema social, não se faz necessário à implantação de instrumentos de punição aos agressores, mais sim, programas de combate à violência e conscientização dos efeitos do bullying, pautados nas lições de respeito mútuo e da igualdade, ensinando para as crianças e os adolescentes, por meios de profissionais da educação e da saúde, a conviverem de forma fraterna, como previsto na Declaração Universal dos Direitos Humanos de 1948, de modo que todos os seres humanos nascem livres e iguais em dignidade e direitos.

Somos todos dotados de razão e consciência e devemos agir em relação uns aos outros com espírito de fraternidade. 
Assim, acredita-se que a paz é um bem de todos, podendo ser alcançada. Porém, para isto, se faz necessário seguir o caminho da fraternidade, o qual é possível encontrar meios para ensinar a juventude a respeitar as diferenças, em conceito de igualdade, respeitando os desiguais, e assim auxiliando o próximo a ter uma vida digna e saudável, combatendo em sua raiz a violência e a degradação social.

\section{REFERÊNCIAS}

ALBINO, Priscilla Linhares; TERÊNCIO, Marlos Golnçalves. Considerações críticas sobre o fenômeno bullying: do conceito ao combate e à prevenção. Revista jurídica do Ministério Público Catarinense, v. 6, n. 15, jul./dez. 2009, Florianópolis, p. 169 $-195$.

ANG, Rebecca P.; TAN, Kit-Aun; MANSOR, Abu Talib. Normative beliefs about aggressive as a mediator of narcissistic exploitativeness and cyberbullying. J Interpers violence, 23 (13), 2010.

AQUINI, Marco. Fraternidade e Direitos Humanos. In: BAGGIO, Antônio Maria (org.). O princípio esquecido/1. Vargem Grande Paulista: Editora Cidade Nova, 2008.

BAGGIO, Antonio Maria. Fraternidade e reflexão politológica contemporânea. In: BAGGIO, Antônio Maria (org.) O princípio esquecido/2: exigências, recursos e definições da fraternidade na política. Tradução de Durval Cordas, Luciano Menezes Reis. Vargem Grande Paulista: Cidade Nova, 2009.

BERGUER, Aurélie; BLAYA, Catherine; BERTHAUD, Julien. Faire de la Cyberviolence un objet scientifique: un challenge pour la communauté de recherche internationale. Colloque « Violences à l'école », Décembre 2011, Arras.

BOBBIO, Noberto. A era dos direitos. 9a . ed. Rio de Janeiro: Elsevier, 2004.

BÖCKENFÔRDE, Ernst-Wolfgang. Grundrechtstheorie und Grundrechtsinterpretation. In: Ernest-Wolfgang Böckenförde, Staat, Verfassung, Demokratie: Studien zur Verfassungstheorie und zum Verfassungsrecht. Frankfurt AM Main, Suhrkamp, 1991, pp. 115-145. 
BONAVIDES, Paulo. Curso de Direito Constitucional. 26. ed. São Paulo: Malheiros, 2011.

CAMBI, Eduardo; OLIVEIRA, Priscila Sutil de. Bullying e cultura da paz. Revista Judiciária do Paraná, ano X, nº 10, novembro 2015, p. 119 - 141.

CHALITA, Gabriel. Pedagogia da amizade. Bullying: o sofrimento das vítimas e dos agressores. $1^{\mathrm{a}}$ ed. São Paulo: Gente, 2008.

DINIZ, Maria Helena. "Bullying”: Responsabilidade civil por dano moral. Marília/ SP: Revista Argumentum, v. 17, pp 17-43, jan.-dez. 2016.

LAMPERT, Claudia; DONOSO, Verónica. Bullying. In: LIVINGSTONE, S.; HADDON, L.; GÖRZIG, A. Children, Risk and Safety on the Internet: Kids Online in Comparative Perspective. Bristol: The Police Press, 2012. pp. 141 - 150.

LAW, D. M., et al. The changing face of bullying: An empirical comparison between traditional and internet bullying and victimization. Computers in Human Behavior , 2011. doi:10.1016/j.chb.2011.09.004

LUCA, Guilherme Domingues de; POZZOLI, Lafayette. A Relação Direito e Fraternidade como instrumento promocional da dignidade da pessoa humana no direito do trabalho. Revista do Direito do Trabalho e Meio Ambiente do Trabalho, v. 1, n. 2, Jul./Dez., 2015, p. 227-246.

MANDIRA, Marielly Rodrigues. Cyberbullying entre estudantes: fatores individuais e do contexto escolar. Programa de Pós-graduação em educação. Universidade Federal do Paraná. Dissertação. Curitiba. 70 p.

MENESINI, Ersilia. Cyberbullying: the right value of the phenomenon. Comments on the paper 'Cyberbullying: an overrated phenomenon.' European Journal of Developmental Psychology. 9 (5). Pp. 544 - 552, 2012.

Muir, Déborah. Violence against children in cyberspace. Bangkok: ECPAT International, 2005.

MONTORO, André Franco. Estudos de filosofia do direito. São Paulo: Editora Revista dos Tribunais, 1999.

OLWEUS, Dan. Cyberbullying: an overrated phenomenon? European Journal of developmental psychology. 2012.9 (5) pp. 1 - 19. Disponível em: http:/ / dx.doi.org /10.1080/17405629.2012.682358 
ORSINI, Adriana Goulart de Sena; SILVA, Lucas Jeronimo Ribeiro da. Da escola ao Poder Judiciário: Reflexões sobre o bullying escolar e a judicialização de conflitos infanto-juvenis. In: SILVA, Juvência Borges; THIBAU, Tereza Cristina Sorice Baracho; MACHADO, Edinilson Donisete. Acesso à justiça I. Florianópolis: Conpedi, 2015, p. 287.

PANCOTTI, Heloísa Helena Silva; RAZABONI JUNIOR, Ricardo Bispo; LEÃO JÚNIOR, Teófilo Marcelo de Arêa. A fundamentalidade dos direitos sociais e a inconstitucionalidade da nova jornada de trabalho. Revista de Direito do Trabalho, vol. 191/2018, p. 125-142, jul. 2018.

PANCOTTI, Luiz Gustavo Boiam. Conflitos de princípios constitucionais na tutela de benefícios previdenciários. São Paulo: LTr, 2009.

PATCHIN, Justin; HINDUJA, Sameer. Bullies move beyond the schoolyard. Youth Violence and Juvenile Justice, Vol. 4 No. 2, April 2006. 148-169 DOI: $10.1177 / 1541204006286288$

POZZOLI, Lafayette; CRUZ, Álvaro Augusto Fernandes da. Princípio Constitucional da Dignidade Humana e do Direito Fraterno. Revista Em Tempo, v. 9, p. 31 -44, setembro, 2010.

POZZOLI, Lafayette; TOLEDO, Iara Rodrigues. Análise do princípio constitucional da dignidade humana face a dimensão da afetividade e o direito fraternal. Problemata: R. Inter. Fil. V.8, n.1, 2017, p. 178-190. DOI:http://dx.doi.org/10.7443/problemata.v8i1.27851.

RAZABONI JUNIOR, Ricardo Bispo; LEÃO JÚNIOR, Teófilo Marcelo de Arêa. Direitos Sociais como Direitos Fundamentais. In: MARGRAF, Alencar Frederico; COSTA, Cleverson Sant'Ana; MARGRAF, Priscila de Oliveira. Direitos Fundamentais: uma abordagem interdisciplinar. Florianópolis: Editora EMais, 2018.

RAZABONI JUNIOR, Ricardo Bispo; MARGRAF, Alencar Frederico; LEÃO JÚNIOR, Teófilo Marcelo de Arêa. Responsabilidade civil de escolas privadas nos casos de Bullying. Revista dos Tribunais, vol. 994/2018, p. 73-94, ago/2018.

ROCHA, Telma Brito. Cyberbullying: ódio, violência virtual e profissão docente. Brasília: Liber livro, 2012.

SANTOS, Erick. O fenômeno bullying e os direitos humanos. Revista de Direito Educacional, vol. 3, jan-jun, 2011, p. 51-107. 
SCHNEIDER, Shari Kessel; O’DONNEL, Lydia; STUEVE, Ann; COULTER, Robert. Cyberbullying, School Bullying, and Psychological Distress: A Regional Census of High School Students. American Journal of Public Health. Vol 102, n. 1, Janeiro de 2012.

SHARIFF, Shaheen. Ciberbullying. Questões e soluções para a escola, a sala de aula e a família. Porto Alegre: Artmed, 2011.

SILVA, José Afonso da. Curso de Direito Constitucional Positivo. $38^{\mathrm{a}}$ ed. atual. São Paulo: Malheiros, 2014.

SILVA, Virgílo Afonso da. A Constitucionalização do Direto: Os direitos fundamentais nas relações entre particulares. $1^{\text {a }}$ Ed. São Paulo: Malheiros, 2005.

SLONJE, R;SMITH,P.K. Cyberbullying: another main type of bullying? Scandinavian Journal of Psychology. 2008 Apr;49(2):147-54. doi: 10.1111/j.1467-9450.2007.00611.x.

TOKUNAGA, Robert S. Following you home from school: a critical review and synthesis of research on cyberbullying victimization. Computers in Human Behavior. 26 (2010) p. $277-287$.

TORRES, Glaucia Cardoso Teixeira; MUNIZ, Tânia Lobo. Assimetrias econômicas e os princípios da solidariedade e da fraternidade como bases valoritivas para seu enfrentamento. Revista Jurídica, v. 2, n. 39, 2015, p. 154-172.

WALKER, Carol; SOCKMAN, Beth Rajan; KOEHN, Steven. An Exploratory Study of cyberbullying with undergraduate university students. TechTrends, March/ April, 2011. vol.55, n. 2, p. $31-38$

ZUIN, Antonio A. S. Violência e tabu entre professores e alunos: a internet e a reconfiguração do elo pedagógico. São Paulo: Cortez, 2012. 